\title{
PERPUSTAKAAN ERA ISLAM KLASIK DAN PERKEMBANGANNYA DI LEMBAGA PENDIDIKAN ISLAM INDONESIA SAAT INI
}

\author{
Afrizal \\ Pustakawan IAIN Imam Bonjol Padang \\ e-mail : afrizalsangir@gmail.com
}

\begin{abstract}
This paper discusses the glory of Islamic civilization in the past through the development of science. Besides that, it also discussed about the condition of the library in Islamic educational institutions in general, which was so concerned and seemed not to get the attention of various parties concerned. In fact, the library is a window of science and information because that is where the user will be able to discover new things
\end{abstract}

Keywords : Islamic Library, Islamic Education

\begin{abstract}
Abstrak :Tulisan ini membahas tentang kejayaan peradaban Islam di masa lampau melalui perkembangan ilmu pengetahuan. Selain itu juga dibahas tentang bagaimana kondisi perpustakaan di lembaga pendidikan Islam secara garis besar yang begitu memperihatinkan dan seakan tidak mendapatkan perhatian dari berbagai pihak terkait. Padahal, perpustakaan adalah jendela ilmu pengetahuan dan informasi karena di sanalah tempat di mana pemustaka akan mampu menemukan berbagai hal baru
\end{abstract}

Kata kunci : Perpustakaan Islam, Pendidikan Islam

\section{A. PENDAHULUAN}

Pada masa kejayaan Islam, perpustakaan menjadi sarana belajar sehingga membuat umat Islam di masa itu mampu membangun sebuah peradaban besar di Jazirah Arab yang bertahan hingga berabad - abad lamanya. Namun demikian, akibat tidak terdokumentasikannya ilmu pengetahuan tersebut berdampak pada tatanan umat Islam, baik dari aspek sosial, politik, ekonomi, maupun budaya yang mengalami stagnasi. Akhirnya umat Islam hanya menjadi semacam "pengikut" bagi bangsa yang dianggap lebih maju, dalam hal ini adalah dunia Barat.

Paparan atas kenyataan tersebut memberi bukti pentingnya perpustakaan di dalam pengembangan suatu peradaban dan bangsa. Banyak sekali ilmu pengetahuan serta informasi yang tersedia di perpustakaan yang bisa dimanfaatkan untuk mencerdaskan umat. Banyak pula literatur yang mengungkap peran perpustakaan sebagai pusat belajar. Fungsi serta peran perpustakaan tersebut kemudian diadopsi oleh perpustakaan - perpustakaan yang ada di belahan Dunia Barat. Mereka mengubah perpustakaan menjadi sebuah "learning center", yang menunjukkan bagaimana perpustakaan mampu menjadi sebuah gerbang pembuka cakrawala ilmu pengetahuan, termasuk bagi umat Islam yang notabene merupakan agama terbesar di dunia.

\section{B. PEMBAHASAN}

\section{Definisi Perpustakaan}


Istilah "Perpustakaan" yang kita kenal selama ini berasal dari kata dasar "pustaka". Secara harfiah bisa diartikan sebagai kitab atau buku. Perpustakaan adalah kumpulan buku buku (Balai Pustaka, 1989: 713). Di dalam bahasa Inggris, perpustakaan dikenal dengan istilah Library yang berasal dari bahasa Latin "Liber" atau "Libri". Dalam perkembangannya, istilah tersebut berkembang menjadi "Librarius" yang maknanya juga Buku.

Dalam berbagai bahasa,
perpustakaan dikenal dengan
Bibliotheek (Belanda), Bibliotheque (Perancis), Bibliothek (Jerman), Bibliotheca (Portugis/Spanyol). Semua istilah tersebut berakar dari bahasa Yunani "Biblia” (Basuki, 1993:3).

Terdapat beberapa definisi tentang perpustakaan, yakni:

1. A room or building where a collection of books and newspapers, or things such as films or records is kept to be used by members (Chambers Essential English Dictionary, 1995)

2. Kumpulan buku, manuskrip dan bahan pustaka lainnya yang digunakan untuk keperluan studi atau bacaan, kenyamanan atau kesenangan (Webster's Third Edition International Dictionary, 1961)

3. A collection of books, or a similar collection of things such as films or records (suatu koleksi dari bukubuku atau semacam koleksi dari benda-benda seperti film atau rekaman-rekaman) (Chambers Essential English Dictionary, 1995)

4. Kumpulan materi cetak dan media non cetak dan atau sumber informasi dalam komputer, yang disusun secara sistematik untuk digunakan pemakai (International Federation of Library Associations and Institutions/IFLA)

5. Unit Perpustakaan, dokumentasi dan informasi adalah unit kerja yang memiliki sumberdaya manusia, ruangan khusus dan koleksi bahan pustaka, sekurang-kurangnya 1000 judul dari berbagai disiplin ilmu yang sesuai dengan jenis perpustakaan yang bersangkutan, dan dikelola menurut sistem tertentu (Keputusan Menteri Negara Pendayagunaan Aparatur Negara Republik Indonesia No. 132/KEP/M.PAN/12/2002).

6. Perpustakaan adalah institusi pengelola koleksi karya tulis, karya cetak, dan/atau karya rekam secara profesional, dengan sistem yang baku guna memenuhi kebutuhan pendidikan, penelitian, pelestarian, informasi dan rekreasi para pemustaka (Undang-Undang Republik Indonesia No. 43 Tahun 2007 tentang Perpustakaan)

7. Perpustakaan adalah kumpulan buku yang tersimpan di suatu tempat tertentu, milik suatu instansi/lembaga tertentu. Di dalam perpustakaan terdapat buku-buku yang bisa dipinjam selama beberapa hari atau minggu, tetapi ada juga yang hanya boleh dibaca di perpustakaan seperti buku-buku referensi (Tedjasudhana, 1990:12).

Dengan berbagai definisi di atas, maka bisa ditarik kesimpulan bahwa Perpustakaan adalah koleksi yang terdiri atas berbagai materi cetak, baik buku, surat kabar, majalah dan media non-cetak berupa disket, Compac Disc, Foto, film dan lain sebagainya, yang 
terpelihara dengan baik serta dimanfaatkan untuk keperluan studi atau belajar mapun sebagai sumber informasi bagi yang membutuhkannya.

Perpustakaan juga bisa diartikan sebagai sebuah ruangan yang merupakan bagian dari gedung atau gedung itu sendiri yang secara khusus dikelola untuk menyimpan, memelihara serta menggunakan berbagai koleksi yang dimiliki, baik yang berupa materi cetak maupun noncetak yang diorganisir secara profesional dengan sistem yang telah dibakukan.

Undang - undang Republik Indonesia Nomor 43 Tahun 2007 menyebut perpustakaan sebagai institusi pengeloa koleksi karya tulis, cetak maupun karya rekam yang dikelola secara profesional dengan menggunakan sebuah sistem baku untuk memenuhi kebutuhan pendidikan, pelestarian, penelitian, informasi dan rekreasi para pemustaka.

\section{Latar Belakang Munculnya Perpustakaan Pada Masa Kejayaan Islam}

Pada masa kejayaan Islam, ada beberapa hal melatarbelakangi pembuatan dan pengelolaan perpustakaan, antara lain:

1. Setelah pengkodifikasian Al Qur'an ke dalam bentuk mushaf, muncul keinginan umat muslim pada masa itu, khususnya yang hidup jauh dari Rasulullah SAW untuk mempelajari dan memahami $\mathrm{Al}$ Qur'an serta ajan Islam sesuai dengan apa yang dipahami dan dilakukan oleh rasul sendiri. hal itu membuat sebagian ulama untuk membukukan sabda sabda Rasulullah. Meski mendapat tentangan dari sebagian yang lain, yang berpedoman pada Hadits yang mengatakan untuk melakukan penulisan terhadap segala hal yang bersumber dari Rasul selain wahyu Al Qur'an, namun Umar bin Abdul Aziz (wafat 675 M) memerintahkan Muhammad bin Muslim bin Syihab az-Zuhri al-Madani (wafat 695 M) agar mengumpulkan hadits untuk kemudian menuliskannya ke sebuah buku. Dirinya beralasan bahwa Rasul melarang penulisan hadits karena merasa khawatir akan tercampur dengan wahyu yang ada di dalam Al Qur'an. Padahal, pada masa itu, Al Qur'an sudah terkodifikasi ke dalam bentuk mushaf sehingga kekhawatiran akan tercampur dengan hadits sudah tidak ada lagi. Setelah dihimpun, hadits - hadits tersebut disebarluaskan ke seluruh penjuru negeri dan dijadikan sebagai referensi.

2. Pada masa Ibn Syihab az-Zuhri, banyak sekali ahli hadits yang rela untuk bepergian jauh hanya untuk mendapatkan sebuah hadits untuk kemudian mereka himpun ke dalam koleksi mereka masing masing. Koleksi - koleksi tersebut kemudian dikenal oleh umat Islam sebagai koleksi Sahih Bukhari, Sahih Muslim, Sunah Abu Daud, Sunnah atTurmudzi dan berbagai koleksi lain. Setiap koleksi hadits 
terdiri atas 3 jilid bahkan lebih hingga mencapai belasan jilid dan keberadaannya kemudian menjadi bahan rujukan bagi umat Islam.

3. Munculnya gerakan penerjemahan yang dipelopori oleh Khalifa al Mansyur pada masa dinasti Abbasiyah yang kemudian menambah jumlah koleksi pustaka pada masa tersebut. Sang Khalifah mempekerjakan orang - orang Parsi (Persia) yang baru saja memeluk Islam untuk melakukan penerjemahan terhadap karya - karya berbahasa Persia, terutama yang membahas bidang ketatanegaraan, politik, astrologi dan moral. Pada masa itu, banyak pula karya - karya penulisan berbahasa Yunani yang diterjemahkan ke dalam bahasa Arab, misalnya karya karya Aristoteles, Ptolemy, Nicomashus dan Euclid. Gerakan penerjemahan terus berlanjut hingga ke masa kekhalifahan selanjutnya, yakni pada masa Al-Makmun. Bahkan, Al-Makmun rela membayar mahal jasa para penterjemah yang bekerja untuk dirinya.

Dengan adanya gerakan gerakan tersebut, bahan pustaka yang dihasilkan menjadi sangat berlimpah sehingga mendorong didirikannya sebuah tempat khusus untuk menyimpannya atau yang saat ini kita kenal dengan istilah perpustakaan. Umat Islam mengenal perpustakaan yang berdiri pertama kali dan bisa diakses oleh masyarakat luas adalah Baitul Hikmah yang bukan hanya berfungsi untuk menyimpan berbagai bahan pustaka, namun juga sekaligus menjadi pusat pengembangan ilmu pengetahuan.

Pada masa kepemimpinan khalifah Harun Al-Rasyid, didirikan sebuah perpustakaan bernama Khizanah al Hikmah yang dimanfaatkan sebagai tempat menyimpan berbagai bahan pustaka sekaligus sebagai pusat penelitian bagi para pemikir Islam. Berdasarkan atas sejarah, Khalifah Al-Makmun, sejak tahun $815 \quad M \quad$ mengembangkan lembaga tersebut, salah satunya adalah dengan mengubah namanya menjadi Bait al-Hikmah. Lembaga tersebut juga dimanfaatkan lebih baik, salah satunya adalah untuk menyimpan berbagai koleksi bahan pustaka kuno yang berasal dari Persia, Etiopia, Bizantium serta India. Tokoh yang ditunjuk untuk menjadi kepala perpustakaan bait alHikmah adalah seorang nasionalis serta ahli Pahlevi, yaitu Sahl ibn Harun.

Pada masa al-Makmun, Bait alHikmah ditingkatkan lagi fungsinya menjadi pusat kegiatan studi, riset astronomi dan matematika. (Hitty, 2006:410)

Disatu sisi perpustakaan Bait al Hikmah ini juga merupakan bagian dari bangunan istana khalifah, yang dilengkapi dengan ruang tersendiri untuk para penyalin, penjilid dan pustakawan.( Terj. Priyono dan Hassan, 1991:49)

\section{Jenis - Jenis Perpustakaan Era Kejayaan Islam}


Untuk lebih mengetahui seluk beluk perpustakaan yang berdiri dan beroperasi pada masa kejayaan Islam, perlu kita tinjau sekilas apa saja jenis perpustakaan yang ada, yaitu:

a. Perpustakaan Umum, yang merupakan perpustakaan yang biasa didirikan di masjid masjid agar umat Islam dapat melakukan kegiatan belajar di masjid. Beberapa perpustakaan umum didirikan dengan maksud agar bisa menampung pelajar yang datang untuk menimba ilmu pengetahuan. Yang termasuk ke dalam jenis perpustakaan umum antara lain Baitul Hikmah, Ibnu Sawwar di Basrah, Al-Haidariyah di AnNajaf, Darul Hikmah di Kairo serta berbagai perpustakaan yang ada di lembaga pendidikan pada masa itu. Koleksi yang dipunyai oleh perpustakaan umum rata - rata adalah berbagai buku agama Islam serta berbagai buku ilmu pengetahuan yang berkembang pada masa itu yang merupakan hasil terjemahan dari berbagai bahasa. Terdapat pula perpustakaan yang menyimpan terjemahan karya penulis dan pemikir besar seperti Hipocrates dan Aristoteles.

Koleksi yang ada pada perpustakaan Umum ini berupa bukubuku ilmu agama Islam dan Bahasa Arab, bermacam-macam ilmu pengetahuan yang berkembang pada masa itu,buku-buku terjemah bahasa Yunani, Persia, Qibty dan Arami, menerjemahkan karya-karya umum termasuk literasi humaniora, bukubuku Aristoteles dan Hipocrates juga dilakukan diperpustakaan Umum. (Yunus, 1996:78)

b. Perpustakaan Semi Umum yakni perpustakaan yang didirikan oleh para Khalifah serta para pemimpin kerajaan yang dimaksudkan untuk menimba ilmu pengetahuan. Beberapa perpustakaan pada masa itu yang termasuk ke dalam Perpustakaan Semi Umum antara lain AlMuzta'sim Billah, An-Nashir Li Dinillah dan Perpustakaan Khalifah- Khalifah Fathimiyah.

Seperti halnya perpustakaan khalifah-khalifah di Cordova, biasanya koleksi pada perpustakaan semi umum ini terdiri dari kitab-kitab fiqih, nahwu, bahasa, hadits, sejarah, hikayat rajaraja, ilmu perbintangan, kerohanian dan ilmu kimia. (Yunus, 1996:80)

Pada saat Arab berhasil menaklukkan tanah Spanyol, mereka kemudian menjadikan Cordova sebagai ibu kota. Kota tersebut kemudian dijadikan sebagai pusat pengembangan kebudayaan serta peradaban. Bahkan, kota Cordova menjelma menjadi kota terbesar kedua di dataran Eropa setelah Konstantinopel.

Karena berada di bawah kendali Islam, berbagai buku berbahasa Yunani yang ada di sana diterjemahkan ke dalam bahasa Arab untuk kemudian dimanfaatkan untuk mengemangkan ilmu pengetahuan di perguruan perguruan tinggi, sekolah - sekolah serta menjadi koleksi perpustakaan Islam. Hasilnya, banyak orang, terutama umat Islam menjadi 
terpelajar. Mereka dididik oleh para sarjana maupun sejarawan yang ada di Andalusia. Bahkan, hampir semua orang bisa membaca maupun menulis. Puncak kejayaan kekhalifahan ini adalah saat berada di bawah komando khalifah Al-Hakam II (961-976M).

Khalifah Al-Hakam sendiri dikenal sebagai salah satu sarjana terbaik. Dirinya juga membangun sebuah perpustakaan yang sangat bagus kemudian mengumpulkan berbagai buku dari segala cabang ilmu pengetahuan. Perpustakaan tersebut dikenal sebagai salah satu yang terbesar pada masanya. Konon, ada lebih dari 400.000 buku di dalam perpustakaan tersebut. Untuk membantu pengguna yang ingin membaca atau menemukan buku yang dicari, perpustakaan tersebut menggunakan katalog yang dibuat dengan sangat detail. Pada masa kepemimpinan Al-Hakam ini pula, berbagai khazanah buku yang belum pernah dimiliki berhasil dikumpulkan.

Hubungan antara kota Cordova dengan Dunia Timur, khususnya Iraq dan Syiria di Jazirah Arab terbangun dengan sangat baik. Pada saat itu, pemerintah Bani Umayyah banyak mengambil buku dan para ilmuwan dan begitu pula sebaliknya. Bahkan, banyak pencari ilmu dari Syiria, Arab dan Iraq yang kemudian berhijrah ke Cordova dan Andalusia hanya demi menemukan sumber ilmu pengetahuan yang mereka cari.

Pada masa Bani Umayyah II, kepustakaan bukan hanya menjadi milik keluarga kerajaan atau daulah, namun juga telah menjadi konsumsi masyarakat luas. Hal itu pulalah yang kemudian terjadi dengan perpustakaan Khalifah yang ada di Kairo, Mesir. Di ibukota Mesir, perpustakaan yang pertama dibangun oleh Khalifah Al Aziz (975 - 996 M). Perpustakaan tersebut diawali dengan adanya perkumpulan orang - orang terpelajar. Mereka kemudian mengumpulkan modal untuk mendirikan sebuah universitas serta sebuah masjid yang sangat terkenal, yakni Al-Azhar. Perpustakaan Kairo memiliki lebih dari 600 ribu buku serta 2.400 koran. Oleh Al Aziz yang dikenal sangat mencintai buku, perpustakaan tersebut dibangun dengan berhiaskan emas dan perak. Setiap koleksi disimpan dengan sangat teratur di bagian atas. Al Aziz bahkan meminta Khalil Ibn Ahmad agar dibuatkan sebuah naskah dari kitab $\mathrm{Al}$ Ain sekaligus memintanya untuk menjadi pustakawan.

c. Perpustakaan Pribadi, Perpustakaan jenis ini biasanya didirikan oleh para ulama dan sastrawan untuk kepentingan mereka sendiri. jumlahnya sangat banyak karena hampir setiap sastrawan dan ulama pasti memilikinya. Mereka menggunAkan perpustakaan tersebut sebagai sumber referensi bagi penelitian dan hasil karya mereka. Beberapa perpustakaan pribadi yang terkenal di masa lampau antara lain Perpustakaan Ibnul Harsyab, Al-Fathu Ibnu Haqam, Al Muwaffaq Ibnul Mathran, Hunain Ibnu Ishaq, AlMubasysir Ibnu Fatik dan Jamaluddin Al Qifthi.

Salah satu perpustakaan pribadi yang terkenal ada di Bukhara yang dimiliki oleh seorang bangsawan. Pada saat itu, Dinasti Samanid berhasil memajukan kebudayaan serta 
pendidikan di propinsi Tran-Oxana yang saat ini termasuk ke dalam wilayah negara Rusia. Salah satu raja paling terkenal di sana adalah Sultan Nuh ibn Mansur yang memimpin pada sekitar abad ke $10 \mathrm{M}$. Di antara sekian banyak hal hebat yang dimiliki, Bukhara dikenal memiliki perpustakaan bangsawan yang menyimpan berbagai koleksi pustaka yang dikumpulkan oleh para leluhur mereka.

Perpustakaan tersebut mendapat tempat istimewa, para sarjana menimba ilmu pengetahuan mereka di sana, salah satunya adalah Avicenna atau oleh umat Islam dikenal dengan nama Abu Ali ibn Sina. Avicenna lahir pada sekitar tahun $980 \mathrm{M}$ atau $370 \mathrm{H}$ di sebuah desa kecil bernama Afshinah, di dekat Bukhara.

Berbagai perpustakaan yang dikelola oleh umat Islam bukan hanya memperhatikan ilmu - ilmu keagamaan, namun juga mengelola disiplin ilmu yang lain, misalnya sosial, kedokteran, politik, kebudayaan, filsafat dan lain sebagainya.

\section{FUNGSI PERPUSTAKAAN PADA MASA KEJAYAAN ISLAM}

Ada banyak sekali peran perpustakaan pada masa peradaban Islam, antara lain sebagai: center.

- Pusat belajar atau learning Setelah masa Khulafaur Rasyidin, peradaban Islam dengan cepat berkembang, salah satunya pada bidang pendidikan yang mencapai puncaknya pada masa Umayyah dan Abbasiyah. Pada saat itu, apresiasi umat Islam terhadap perpustakaan sangat tinggi. Banyak ulama yang membangun perpustakaan, baik yang bersifat umum, maupun semi umum dan pribadi. Hampir setiap masjid kemudian memiliki perpustakaan. Umat Islam yang hidup pada masa itu menganggap perpustakaan sebagai sesuatu hal yang sangat penting, sehingga kadang fungsinya sulit dibedakan dengan fungsi lembaga pengajaran atau pendidikan.

\section{PUSAT PENELITIAN}

Peran perpustakaan sebagai pusat penelitian lebih dirasakan pada masa awal peradaban Islam. Hal tersebut bisa dilihat dari banyaknya peristiwa peristiwa penting, misalnya saat utusan atau orang kepercayaan raja dan khalifah membahas bidang keilmuan tertentu di perpustakaan perpustakaan terkenal, seperti Baitul Hikmal dan Darul Hikmah. Banyak pula peneliti maupun cendekiawan muslim yang mencoba untuk mengembangkan ilmu pengetahuan di perpustakaan. Tidak sedikit dari mereka yang rela berpindah dari satu perpustakaan ke perpustakaan lain hanya untuk menemukan rujukan atas penemuan - penemuan baru.

- Pusat Penerjemahan

Perpustakaan pada masa kejayaan Islam menjadi jembatan bagi kebudyaaan yang berbeda. Salah satu wujud peran tersebut adalah ketika banyak buku - buku atau karya penulisan berbahasa Yunani, Persia, dan yang lainnya dialihbahasakan ke dalam bahasa Arab. Pada masa tersebut, penerjemah mendapat tempat istimewa dan sangat dihormati oleh masyarakat. Kurd Ali mengungkapkan bahwa orang yang pertama kali 
menekuni bidang penerjemahan adalah Chalid ibn Jazid. Banyak sumber lain yang juga menyebut bahwa Chalid ibn Jazid memiliki ketertarikan yang sangat besar terhadap buku - buku lama, khususnys buku - buku yang membahas bidang kimia, kedokteran serta ilmu perbintangan atau astronomi.

Dalam bidang penerjemahan, aktivitas penerjemahan mencapai puncaknya pada masa al-Makmun, khalifah ini juga seorang cendekiawan yang sangat besar perhatiannya kepada ilmu pengetahuan. (Munthoha dkk, 2002:40)

Perpustakaan sebagai pusat penelitian bisa kita lihat salah satunya dengan munculnya Avicenna sebagai salah satu tokoh penting di dunia kedokteran modern. Dirinya dikenal banyak melakukan penelitian maupun pengumpulan bahan di perpustakaan yang dia kunjungi, terutama di Bukhara. Perpustakaan sebagai pusat penelitian masih dilakukan hingga saat ini, terbukti dengan banyaknya pelajar yang memanfaatkannya untuk mencari sumber referensi untuk karya yang akan mereka hasilkan.

Pada masa kejayaaan Islam, alat atau mesin pencetak buku belum ditemukan. Hal itu membuat proses seleksi penyalinan dilakukan oleh hampir setiap perpustakaan besar. Pekerjaan penyalinan buku dilakukan oleh para penyalin yang memiliki tulisan tangan baik dan memiliki etos kerja tinggi. Oleh karena itulah, kehancuran perpustakaan Islam dimulai ketika terjadi banyak perang yang mengakibatkan tidak sedikit para penyalin buku yang gugur di medan perang. Misalnya saja terjadinya Perang Salib yang kemudian membuat kehancuran perpustakaan Tripoli. Selain Al Qur'an, penghancuran perpustakaan tripoli juga menyasar karya - karya cendekiawan muslim terkenal.

\section{PERAN PERPUSTAKAAN DALAM PENDIDIKAN ISLAM MASA KINI}

Pendidikan harus diakui merupapakan sesuatu yang teramat sangat penting karena merupakan akar peradaban sebuah bangsa. Pendidikan adalah kebutuhan pokok setiap orang agar dapat menjawab berbagai tantangan di dalam kehidupannya. Untuk bisa menimba ilmu atau mendapatkan pendidikan, ada banyak cara yang bisa dilakukan, salah satunya adalah dengan melalui perpustakaan.

Sejarah Islam mencatat bahwa perpustakaan memegang peranan yang sangat penting di dalam perkembangannya. Hal itu terjadi tidak lain karena perpustakaan menyimpan berbagai informasi dan referensi ilmu pengetahuan. Hal ini sesuai dengan perpustakaan itu sendiri yaitu hasil budaya dan catatan (record) perjalanan ummat manusia. (Junaedi, 2005; 40)

Seiring dengan perkembangan jaman, kini koleksi atau bahan pustaka yang ada di perpustakaan bukan hanya terbatas pada produk hasil cetakan saja, namun juga telah berkembang kepada berbagai bentuk media noncetak. Masuknya komputer kemudian membuat wajah perpustakaan berubah drastis, sehingga saat ini perpustakaan mampu memberikan pelayanan yang lebih efektif dan efisien. Masuknya computer ke perpustakaan merubah drastis wajah perpustakaan dari 
perpustakaan yang memberikan pelayanan secara manual menjadi perpustakaan yang terotomasi, dari perpustakaan yang dibatasi dengan dinding dan ruangan menjadi perpustakaan tanpa batas yang dilengkapi dengan sarana prasarana elektronik untuk mengakses informasi dalam berbagai format dari berbagai sumber di seluruh dunia. (Rahayuningsih, 2007; 2).

Menurut Perpustakaan Nasional (2006;75), perpustakaan memiliki beberapa peran, yaitu:

1. Secara umum perpustakaan merupakan sumber informasi, pendidikan, penelitian, preservasi dan pelestarian khasanah budaya bangsa serta tempat rekreasi yang sehat, murah dan bermanfaat.

2. Perpustakaan merupakan media atau jembatan yang berfungsi menghubungkan antara sumber informasi dan ilmu pengetahuan yang terkandung di dalam koleksi perpustakaan dengan para pemakainya.

3. Perpustakaan mempunyai peranan sebagai sarana untuk menjalin dan mengembangkan komunikasi antara sesama pemakai, dan antara penyelenggara perpustakaan dengan masyarakat sekitar.

4. Perpustakaan dapat pula berperan sebagai lembaga untuk mengembangkan minat baca, kegemaran membaca, kebiasaan membaca, dan budaya membaca, melalui penyediaan beerbagai bahan bacaan yang sesuai dengan keinginan dan kebutuhan para peserta didik.

5. Perpustakaan dapat berperan aktif sebagai fasilitator, mediator, dan motivator bagi mereka-mereka yang ingin mencari, memanfaatkan, dan mengembangkan ilmu pengetahuan dan pengalamannya.Perpustakaan merupakan agen perubahan (center of changes), agen pembangunan, dan agen kebudayaan ummat manusia. Sebab berbagai penemuan, sejarah, pemikiran dan ilmu pengetahuan yang telah ditemuka dimasa lalu, yang direkam dalam bentuk tulisan atau bentuk tertentu yang di simpan di perpustakaan. Koleksi tersebut dapat dipelajari, diteliti, dikaji, dan dikembangkan oleh generasi sekarang dan akan datang.

6. Perpustakaan berperan sebagai lembaga pendidikan nonformal bagi anggota masyarakat dan pengunjung perpustakaan. Mereka dapat belajar secara mandiri (otodidak), melakukan penelitian, menggali, emanfaatkan dan mengembangkan sumber informasi dan ilmu pengetahuan.

7. Petugas perpustakaan dapat berperan sebagai pembimbing dan memberikan konsultasi kepada pemakai atau melakukan pendidikan pemakai (user's education), dan pembinaan serta menanamkan pemahaman tentang pentingnya perpustakaan bagi orang banyak. 
8. Perpustakaan berperan dalam menghimpun dan melestarikan koleksi bahan pustaka agar tetap dalam keadaan baik semua hasil karya ummat manusia yang tidak ternilai harganya.

9. Perpustakaan dapat berperan sebagai ukuran (barometer) atas kemajuan masyarakat dilihat dari intensitas kunjungan dan pemakaian perpustakaan. Sebab masyarakat yang sudah maju dapat ditandai dengan adanya perpustakaan yang sudah maju pula, sebaliknya masyarakat yang sedang berkembang belum memiliki perpustakaan yang memadai dan representative.

10. Secara tidak langsung, perpustakaan yang berfungsi dan telah dimanfaatkan dengan sebaik-baiknya, dapat ikut berperan dalam mengurangi dan mencegah kenakalan remaja, dan tindak disipliner.

Yang menjadi pertanyaan sekarang adalah apakah perpustakaan yang ada di lembaga pendidikan Islam sudah mampu mengemban tugasnya?

Harus diakui bahwa sebagian besar perpustakaan yang ada di lembaga pendidikan Islam kondisinya cukup memperihatinkan. Kita bisa melihat bahwa perpustakaan seakan menjadi satu tempat yang sangat terisolir, bukan hanya karena letaknya yang biasanya berada di sudut terpencil lembaga pendidikan namun juga karena masih dianggap sebagai suatu ruangan yang kurang nyaman. Banyak pula perpustakaan di lembaga pendidikan yang koleksinya masih sangat terbatas. Di sisi lain, minat baca pelajar juga terbilang masih sangat rendah.

Menurut Arief Furchan (2004; 51) yang paling bertanggung jawab atas hal ini adalah pertama, kepala lembaga pendidikan dan pengurus yayasan, kedua, guru, karyawan, siswa serta orang tua siswa.

Dengan kondisi semacam itu, bukan tidak mungkin umat Islam akan terus mengalami kemunduran dan cap atau stigma bahwa umat Islam adalah "umat pengikut" akan semakin lekat.

Ada beberapa langkah yang dapat dilakukan untuk mengatasi keterpurukan perpustakaan masa kini, khususnya di lembaga pendidikan Islam, di antaranya:

- Semua pihak terlibat mengetahui segala persoalan yang dihadapi oleh perpustakaan untuk kemudian membuat rencana pengembangan perpustakaan.

- Menyepakati sasaran yang ingin dicapai, di dalam penetapan sasaran ini haruslah didasarkan pada kondisi sebenarnya dengan memanfaatkan segala potensi yang ada. Setelah sasaran tersebut jelas bagi semua pihak, tugas selanjutnya bagi para stakeholder adalah menggerakkan semua sumber daya manusia yang ada untuk mencapainya.

- Pihak lembaga pendidikan harus mengadakan kerjasama dengan pihak luar yang diharapkan mampu memberikan jalan keluar, misalnya saja pihak pustakawan (librarian) yang dapat memberikan pembinaan dan 
pelatihan guru yang bekerja di perpustakaan sebagai guru pustakawan.

- Pihak lembaga pendidikan harus mengalokasikan budget untuk menambah koleksi perpustakaan yang meliputi: buku teks, fiksi, non fiksi, majalah dan lain sebagainya sekaligus mencari dana dari donator untuk mengembangkan perpustakaan.

- Orang tua, guru dan masyarakat harus bisa memotivasi serta menanamkan pada anak pentingnya membaca dan melestarikan budaya membaca, dan mendorong mereka untuk meramaikan perpustakaan.

Lembaga pendidikan Islam mempunyai tiga fungsi, yaitu: satu. Sebagai media penyampai pengetahuan agama (transfer of Islamic knowledge); dua. sebagai media pemelihara tradisi Islam (maintenance of Islamic tradition); tiga. Sebagai media pencentak ulama (reproduction of ulama).(Ramayulis, 2009; 92).

Ketiga fungsi lembaga pendidikan Islam di atas akan bisa diraih salah satunya apabil memiliki perpustakaan yang memadai serta minat membaca peserta didik tinggi. Seperti halnya di masa lampau, ketika peradaban Islam mencapai masa keemasannya, berbagai bidang ilmu pengetahuan dan teknologi berkembang begitu pesat, hanya karena adanya perpustakaan yang menyimpan berbagai jenis bahan pustaka. Dan, belumlah terlambat untuk memperbaiki kemunduran tersebut mengingat saat ini bahan pustaka sudah semakin beragam dan lebih mudah diakses. Kini, hanya tinggal bagaimana para stakeholder di lembaga pendidikan Islam meningkatkan minat baca kepada para peserta didik.

\section{KESIMPULAN}

Peradaban Islam pernah mencapai masa kejayaan di masa lalu. Salah satu faktor yang menyebabkannya adalah keberadaan perpustakaan yang dibangun oleh para penguasa dan berbagai kebijakan yang dibuat yang berpihak pada ilmu pengetahuan. Sejarah mencatat bahwa peradaban Islam adalah salah satu yang paling maju dan paling disegani, bukan hanya karena keberhasilannya menaklukkan belahan dunia berbeda, namun juga karena kemajuan di bidang ilmu pengetahuan.

Di sisi lain, sejak kehancuran perpustakaan - perpustakaan Islam akibat perang, peradaban Islam bisa dikatakan terus mengalami kemunduran. Bahkan, lembaga pendidikan Islam, terutama yang ada di Indonesia memiliki perpustakaan yang kondisinya cukup memperihatinkan. Sebagai salah satu tonggak kemajuan umat Islam, lembaga pendidikan hendaknya menaruh kepedulian terhadap kondisi perpustakaan mereka dengan merangkul seluruh pihak terkait sekaligus meningkatkan minat baca, terutama kepada peserta didik agar umat Islam tidak semakin terbelakang.

\section{DAFTAR KEPUSTAKAAN}

Abuddin Nata, Al-Qur'an dan Hadits, (Raja Grafindo, Jakarta, 2000)

Al-'Ulum; Vol. 2, Tahun 201341 Ramayulis dan Samsul Nizar, Filsafat Pendidikan Islam, 
(Kalam Mulia, Jakarta, 2009), h 92

Arif Furchan, Transformasi Pendidikan Islam Di Indonesia, (Gama Media, Jogyakarta, 2004)

Departemen Agama RI, Al-Qur'an dan Terjemahannya (Yayasan Penyelenggara Penterjemah alQur'an, Jakarta, 1971)

Departemen Pendidikan dan Kebudayaan, Kamus Umum BesarBahasa Indonesia, Jakarta; Balai Pustaka, 1989

Litian DTedjasudhana, Ensiklopedi Nasional Indonesia, Jakarta; PTCipta Adi Pustaka, 1990

Mahfud Junaedi, Rekonstruksi Sejarah Pendidikan Islam, (Direktorat Kelembagaan Agama Islam, Departemen Agama RI, 2005)

Mahmud Yunus,Sedjarah Pendidikan Islam, Jakarta: Mutiara, 1996

Mastuhu, Dinamika Sistem Pendidikan Pesantren, (INIS, Jakarta, 1994)

Muhammad Athiyah al-Abrasi, AlTarbiyah al-Islamiyah waFalasafatuha, (Isa al-Babi alHalabi, Mesir, 1975)

Mukhtar Yahya dan Fatchurrahman, Dasar-Dasar Pembinaan Hukum Islam, (AlMa'arif, Bandung, 1986)

Munthoha dkk, Pemikiran dan Peradaban Islam, Yogyakarta; UIIPress, 2002
Perpustakaan Nasional RI, Pedoman Penyelenggaraan Umum, (Jakarta, 2006)

Philip K. Hitty,History of The Arabs; froms the earliest time to thepresent, Terj.

R. Cecep Lukman Yasin dan Dedi Slamet RiyadiJakarta: Serambi Ilmu Semesta, 2006

Sulistyo Basuki, Pengantar Ilmu Perpustakaan, Jakarta; PT. Gramedia,1993

Ramayulis, Ilmu Pendidikan Islam, (Kalam Mulia, Jakarta, 2008)

Rahayuningsih, Pengelolaan Perpustakaan, (Graha Ilmu, Yogjakarta, 2007)

Zarnuji, Ta'lim al-Muta'allim Thariq al-Ta'allum, (Toha Putra, Semarang, $\mathrm{tt}$ )

Zianuddin Sartar, Tantangan Dunia Islam Abad 21, Terj. AE Priyono dan Ilyas Hassan, Bandung: Mizan, 1991 